\title{
Periapical injection of betamethasone to control postoperative pain in emergency endodontic care - a randomized double blind clinical trial
}

\author{
Marcos LP Pinheiro', Ricardo Lopes-Rocha², Eduardo D. de Andrade ${ }^{3}$ \\ ${ }^{1} \mathrm{PhD}$, Department of Basic Sciences, Biologic and Health Sciences Faculty, Universidade Federal dos Vales do Jequitinhonha e Mucuri, Diamantina, \\ Minas Gerais State, Brazi \\ ${ }^{2} \mathrm{MSc}$, Department of Dentistry, Biologic and Health Sciences Faculty, , Universidade Federal dos Vales do Jequitinhonha e Mucuri, Diamantina, \\ Minas Gerais State, Brazil \\ ${ }^{3} \mathrm{PhD}$, Department of Pharmacology, Anesthesiology and Therapeutics, Piracicaba Dental School, Universidade Estadual de Campinas, Piracicaba,
}

São Paulo State, Brazil

Received for publication: December 6, 2016 Accepted: May 5, 2017

Correspondence to: Dr. Marcos Luciano Pimenta Pinheiro Rua da Glória, 187, Centro Diamantina city

Minas Gerais State, Brazil email: marcospimenta@ufvjm.edu.br Fone number: +55 03835321200 - Ramal

\begin{abstract}
Aim: the objective of this study was to evaluate the effect of betamethasone in the control of postoperative pain in patients undergoing endodontic treatment. Methods: patients of both genders $(n=120)$, after being submitted to emergency endodontic treatment, received a single dose of betamethasone solution $(0.05 \mathrm{mg}$ / body weight) or sterile saline solution intramucosally, in the periapical region of the treated tooth. The study evaluated the intensity of pain experienced by the patient and the number of analgesics consumed during periods of 4, 24 and 48 hours after endodontic treatment. To compare the level of pain among the groups and the use of analgesics the Fisher's Exact Test was used, adopting a significance level of $95 \%$. Results: patients who received betamethasone felt less pain in 4 hours $(p=0.0177)$ and 24 hours $(p=0.0012)$ compared to those who received the placebo. Conclusions: betamethasone at a dose of $0.05 \mathrm{mg} /$ body weight administered in the periapical region is a advantageous protocol due to its effectiveness, and also because of the comfort it provides to patients in the prevention or control of inflammatory pain in endodontics.
\end{abstract}

Keywords: Betamethasone, Endodontics, Pain.

\section{Introduction}

The presence of pain, swelling or both after endodontic treatment is a condition defined as flare-up, with prevalence of $16 \% 1$ and a multifactorial etiology of mechanical, chemical and microbial processes that occur during the procedure ${ }^{1,2}$. Also influential are the location of the tooth in question, the number of clinic visits and the condition of tooth and periapex before treatment ${ }^{2}$.

Patients seeking endodontic treatment in teeth that already present periapical radiolucency are up to nine times more likely to experience flare-up than those who did 
not have this condition ${ }^{3}$; and those who undergoing multiple visits have a higher risk; up to three times more chance of developing flare-ups ${ }^{4}$. As endodontic treatment does not immediately or totally eliminate periapical inflammatory reaction during the procedure itself, harmful substances such as bacterial toxins can escape from the root canal system into the periapex, causing the persistence of pain in the postoperative period ${ }^{5,6}$.

Corticosteroids are potent anti-inflammatory drugs that suppress inflammatory phenomena as pain and edema ${ }^{7}$. Thus, the use of this drug is an effective supplement to reduce of these symptons after endodontic treatment 8 , and its use in the treatment and prevention of pain and endodontic post-treatment swelling has been shown to be effective and safe ${ }^{8-16}$. Among the corticosteroids, betamethasone has fast, potent and long-lasting action, a dose of $0.5 \mathrm{mg}$ being necessary for an equivalent $20 \mathrm{mg}$ of endogenous hydrocortisone ${ }^{17}$, without causing the undesirable mineralocorticoid activity of sodium retention ${ }^{11}$ and it is even more effective than dexamethasone, equivalent dose of which is $0.75 \mathrm{mg}^{17}$. The hypothesis is that the use of betamethasone is as good or better than the use of dexamethasone, which is already well documented in clinical studies ${ }^{8-14,16}$.

Nobuhara et al. ${ }^{16}$ (1993) developed an experimental model to study the effects of dexamethasone on the periapical tissues of rats after endodontic overinstrumentation. These authors demonstrated by means of histological techniques that the submucosal infiltration of dexamethasone in the periapical region of the mandibular molars produces a significant antiinflammatory effect characterized by the inhibition of neutrophil migration to the periapical tissues.

Extrapolating to the clinic, the administration of a corticosteroid through intrabuccal infiltrative injection would be a technique that would offer great familiarity to the dentist without the need for specialized equipment. Furthermore, it is assumed that optimum levels of the medication would be obtained in the inflamed region, with the further advantage of the application being painless, since at the time of infiltration the region would be anesthetized.

The objective of this randomized double-blind clinical trial was to evaluate the effect of the systemic administration of betamethasone - through infiltration in the oral mucosa - to control pain and edemas in patients undergoing emergency endodontic treatment.

\section{Material and methods}

The design of this randomized, double-blind clinical trial was conducted in full compliance with the ethical principles of the Helsinki Declaration, was approved by the Research Ethics Committee of the Piracicaba Dental School, State University of Campinas, under the protocol 007/2004, and was conducted in accordance with the Consolidated Standards of Reporting Trials statement. It is registered at clinicaltrials. gov with number NCT02865746. (https://clinicaltrials.gov/ct2/ results?term $=$ NCT $+02865746 \&$ Search $=$ Search). Participants were informed about the purpose of the study, agreed to participate and signed the Term of Free and Informed Consent.

\section{Sample}

To calculate the sample, data obtained by Krasner and Jackson $^{13}$ (1986) was used. By adopting a significance level of $95 \%$ and power of test of $90 \%$, the study reached the minimum sample size of 54 subjects per group. This number was increased by $10 \%$ to compensate for occasional losses, totaling 60 subjects per group.

\section{Eligibility criteria}

Inclusion criteria: to be included in the sample individuals had to have a tooth with pain of endodontic origin, diagnosed clinically and radiographically as irreversible pulpitis or necrosis associated to pericementitis and presence of pain, justifying emergency care.

They had to provide a general health history without alterations, and have no condition, local or systemic, that counterindicates the use of the drugs applied in this research study.

Exclusion criteria: individuals who presented any of the following conditions were not included in the study - pregnancy or lactation; use of corticosteroids; history of hypersensitivity to the drugs used in this study; pain associated with abscesses of endodontic origin; or anyone having any of the following diseases: tuberculosis, systemic fungal infections, simple ocular herpes, glaucoma, acute psychosis or psychotic tendencies.

\section{Operative procedures}

Emergency endodontic care was carried out in all patients, in a single session, by students majoring in dentistry, who were previously trained and assisted by a teacher for this study.

\section{Local anesthesia}

A local anesthesia technique adequate to the tooth in question was applied, the solution used being lidocaine based at $2 \%$, with epinephrine at proportion 1:100,000 (ALPHACAINE ${ }^{\circledR}$ - DFL Industry and Trade Ltd.), limiting the use to a maximum of 3.6 $\mathrm{mL}$, equivalent to two vials of this anesthetic. Two anesthetic tubes were used because it is the procedure recommended in the Endodontics Clinic of the School of Dentistry of Piracicaba - Unicamp. Individuals who required more tubes were removed from the study.

\section{Endodontic procedures}

After a diagnostic x-ray, the procedure to remove the carious dentin began, as well as the reconstruction of any lost wall that could compromise the isolation with the use of a rubber dam. The emergency endodontic procedure was carried out through the implementation of the first phase of the chemical-mechanical preparation by using the hybrid technique described by Valdrighi et al. ${ }^{18}$ (1991). A cotton ball was placed at the entrance of the canals, and these were then sealed with a temporary restorative material (Cotosol ${ }^{\circledR}$ - Vigodent - Rio de Janeiro, Brazil). After removal of rubber dam isolation, the occlusion of the patient was checked. Quently, the patients received the drug prescription to be used in case of pain, they were given the following steps to carry out the remainder of the endodontic treatment and were discharged. 


\section{Formation of study groups and randomization}

The random allocation of patients was carried out by means of a draw. 120 opaque equal envelopes were prepared. 60 of them, contained a piece of paper with the number "1" written on it, and the other 60 contained the number " 2 ". All envelopes were sealed, mixed and stored. After endodontic procedures, one of the envelopes was randomly selected for each patient in order to allocate them to group "1" or group "2", by a person who was not directly involved in the patients evaluation.

Group 1 - received the injection of solution "1", of betamethasone disodium phosphate at a concentration of $4 \mathrm{mg} /$ $\mathrm{ml}$ (Celestone injetável® - ampoules 4mg / ml - Chemical and Schering Plough Pharmaceuticals A / S).

Group 2 - received the injection solution "2", of sterile saline solution (sodium chloride $0.9 \%$ - $1 \mathrm{ml}$ ampoules)

To calculate the volume of the solution to be injected, the concentration of betamethasone solution was used in the proportion of $0.05 \mathrm{mg} / \mathrm{kg}$. Thus, for an $80 \mathrm{~kg}$ patient, the maximum volume of solution administered was $1 \mathrm{ml}$. Patients weighing over $80 \mathrm{~kg}$ received the same volume. The injections were performed with the aid of syringes fitted with ultrafine needles (BD ultrafine U-100, 0.3 x $8 \mathrm{~mm}$ ), submucosally near the tooth's periapex of the periapical region of the tooth involved, by using the submucosal infiltration technique.

\section{Blinding of information}

The solutions were placed in similar ampoules containing 1 $\mathrm{ml}$ of solution and labeled merely with numbers "1" or "2". Only the responsible pharmacist knew the content of the ampoules and this professional was not directly involved in the procedures. This information was kept in a sealed envelope and was made available only after the end of statistical analysis. Thus, the patient and the investigator remained blinded to the type of drug used until the end of statistical analysis.

\section{Postoperative care}

At the end of the session, three pills of dipirona (sodium metamizol) (tablets of $500 \mathrm{mg}$, Generic Medicine) were provided to each patient, to take after the effects of the local anesthesia ceased if they felt pain or discomfort. In case of persistent pain for longer periods, subjects also received a prescription for analgesics to be taken at intervals of four hours.

\section{Evaluation method of postoperative pain and analgesic use}

In the periods of 4, 24 and 48 hours after treatment, each patient was contacted by phone to answer two questions, and they were instructed to write down the answers on a card (Point Verbal Rating Scale - Modified VRS4 - Jensen et al., 1986) ${ }^{19}$. The questions were:

\section{1 - How's your toothache?}

a) It passed and I do not feel any more pain

b) I still feel a certain discomfort

c) Only hurts when I touch or chew (above 3 until 6);

d) It got worse, the pain is severe (above 6 until 9).

\section{2 - How many analgesic pills have you taken so far?}

a) None;

b) 1 ;

c) 2 ;

d) 3 or more.

Another question was whether they had experienced any of the possible side effects of the medication.

\section{Statistical analysis}

After a descriptive analysis of the data, the presence of pain or discomfort among the groups was compared, considering the age and gender by using the Fisher's Exact Test. To compare the consumption of analgesics among the groups the Fisher's exact test was also used, considering a significance level of $95 \%$.

\section{Results}

The sample consisted of individuals who came to the Emergency Service of the Dentistry College of Piracicaba, Unicamp, with endodontic pain symptoms. From a total of 120 individuals, 44 were men (36.7\%) and 76 women (63\%); age ranged from 10 to 72 years, constituting an average of 30.89 years $(\mathrm{sd} \pm 3.7)$. Pulpitis was diagnosed in 73 patients $(60.8 \%)$ and necrosis in $47(39.2 \%)$. There was no waiver of any patient.

The list of individuals who reported different pain intensities (no pain, mild pain, moderate pain and severe pain) at the intervals of 4, 24 and 48 hours is itemized in Table 1. Table 2 discriminates the distribution of subjects in relation to the quantity of ingested analgesics, when comparing the groups.

When comparing gender, there were no statistically significant differences in postoperative pain reports.

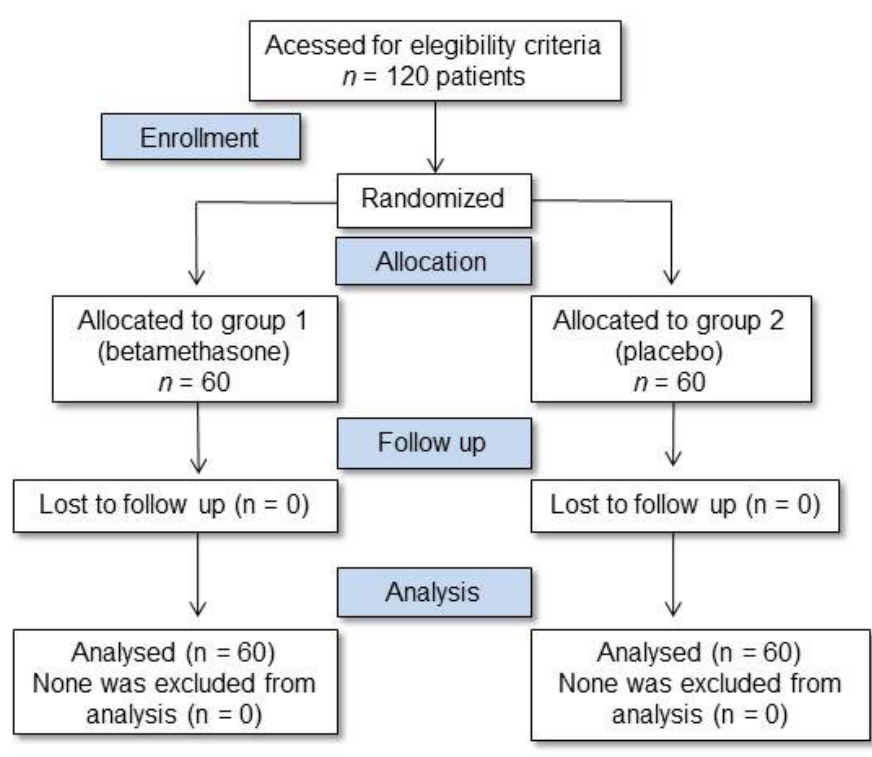

Fig. 1 - Flow diagram according to CONSORT statement. 
Table 1 - Distribution of patients in relation to the degree of reported pain intensity according to postoperative time and treatment groups.

\begin{tabular}{|c|c|c|c|c|c|c|c|c|c|}
\hline \multirow[b]{2}{*}{$\begin{array}{l}\text { Intensity of pain } \\
\text { Postoperative time }\end{array}$} & \multicolumn{4}{|c|}{ BETAMETHASONE $(n=60)$} & \multicolumn{5}{|c|}{$\operatorname{PLACEBO}(n=60)$} \\
\hline & $\begin{array}{l}\text { None } \\
\mathrm{n}(\%)\end{array}$ & $\begin{array}{l}\text { Mild } \\
\mathrm{n}(\%)\end{array}$ & $\begin{array}{l}\text { Mod } \\
\mathrm{n}(\%)\end{array}$ & $\begin{array}{l}\text { Sev } \\
\mathrm{n}(\%)\end{array}$ & $\begin{array}{l}\text { None } \\
\mathrm{n}(\%)\end{array}$ & $\begin{array}{l}\text { Mild } \\
\mathrm{n}(\%)\end{array}$ & $\begin{array}{l}\text { Mod } \\
\mathrm{n}(\%)\end{array}$ & $\begin{array}{l}\text { Sev } \\
\mathrm{n}(\%)\end{array}$ & $p$ \\
\hline 4 hours & $\begin{array}{c}46 \\
(76.7)\end{array}$ & $\begin{array}{c}9 \\
(15.0)\end{array}$ & $\begin{array}{c}1 \\
(1.67)\end{array}$ & $\begin{array}{c}4 \\
(6.67)\end{array}$ & $\begin{array}{c}30 \\
(50.0)\end{array}$ & $\begin{array}{c}14 \\
(23.3)\end{array}$ & $\begin{array}{c}7 \\
(11.67)\end{array}$ & $\begin{array}{c}9 \\
(15.0)\end{array}$ & $0.012^{*}$ \\
\hline 24 hours & $\begin{array}{c}53 \\
(88.33)\end{array}$ & $\begin{array}{c}6 \\
(10.0)\end{array}$ & $\begin{array}{c}1 \\
(1.67)\end{array}$ & - & $\begin{array}{c}37 \\
(61.67)\end{array}$ & $\begin{array}{c}12 \\
(20.0)\end{array}$ & $\begin{array}{c}6 \\
(10.0)\end{array}$ & $\begin{array}{c}5 \\
(8.33)\end{array}$ & $0.004^{*}$ \\
\hline 48 hours & $\begin{array}{c}57 \\
(95.0)\end{array}$ & $\begin{array}{c}3 \\
(5.0)\end{array}$ & - & - & $\begin{array}{c}53 \\
(88.33) \\
\end{array}$ & $\begin{array}{c}3 \\
(5.0) \\
\end{array}$ & $\begin{array}{c}4 \\
(6.67)\end{array}$ & - & 0.13 \\
\hline
\end{tabular}

None = no pain; Mild = small discomfort; Mod (moderate) = pain when touched or chew; Sev (severe) = intense pain (VRS4)

* Significant values for Fisher's Exact Test

Table 2 - Distribution of patients in relation to the number of ingested analgesics according to postoperative time and treatment groups.

\begin{tabular}{|c|c|c|c|c|c|c|c|c|c|}
\hline & \multicolumn{4}{|c|}{ BETAMETHASONE $(n=60)$} & \multicolumn{5}{|c|}{$\operatorname{PLACEBO}(n=60)$} \\
\hline $\begin{array}{l}\text { Number of analgesics } \\
\text { Postoperative time }\end{array}$ & $\begin{array}{c}0 \\
\mathrm{n}(\%)\end{array}$ & $\begin{array}{c}1 \\
n(\%)\end{array}$ & $\begin{array}{c}2 \\
n(\%)\end{array}$ & $\begin{array}{c}3 \text { or more } \\
n(\%)\end{array}$ & $\begin{array}{c}0 \\
n(\%)\end{array}$ & $\begin{array}{c}1 \\
n(\%)\end{array}$ & $\begin{array}{c}2 \\
n(\%)\end{array}$ & $\begin{array}{c}3 \text { or more } \\
n(\%)\end{array}$ & $p$ \\
\hline 4 hours & $\begin{array}{c}49 \\
(81.67)\end{array}$ & $\begin{array}{c}11 \\
(18.33)\end{array}$ & - & - & $\begin{array}{c}31 \\
(51.67)\end{array}$ & $\begin{array}{c}27 \\
(45.0)\end{array}$ & $\begin{array}{c}2 \\
(3.33)\end{array}$ & - & $0.002^{*}$ \\
\hline 24 hours & $\begin{array}{c}55 \\
(91.67)\end{array}$ & $\begin{array}{c}5 \\
(8.33)\end{array}$ & - & - & $\begin{array}{c}41 \\
(68.33)\end{array}$ & $\begin{array}{c}17 \\
(28.33)\end{array}$ & $\begin{array}{c}2 \\
(3.33)\end{array}$ & - & $0.005^{\star}$ \\
\hline 48 hours & $\begin{array}{c}57 \\
(95.0)\end{array}$ & $\begin{array}{c}3 \\
(5.0) \\
\end{array}$ & - & - & $\begin{array}{c}55 \\
(91.67) \\
\end{array}$ & $\begin{array}{c}4 \\
(6.67) \\
\end{array}$ & $\begin{array}{c}1 \\
(1.67) \\
\end{array}$ & - & 0.55 \\
\hline
\end{tabular}

* Significant values for Fisher's Exact Test

\section{Discussion}

The sample consisted of individuals who came to the Emergency Service of the Dentistry College of Piracicaba, Unicamp, with endodontic pain symptoms. From a total of 120 individuals, 44 were men (36.7\%) and 76 women $(63 \%)$; age ranged from 10 to 72 years, constituting an average of 30.89 years (sd \pm 3.7$)$. Pulpitis was diagnosed in 73 patients $(60.8 \%)$ and necrosis in 47 (39.2\%). There was no waiver of any patient.

The list of individuals who reported different pain intensities (no pain, mild pain, moderate pain and severe pain) at the intervals of 4,24 and 48 hours is itemized in Table 1. Table 2 discriminates the distribution of subjects in relation to the quantity of ingested analgesics, when comparing the groups.

When comparing gender, there were no statistically significant differences in postoperative pain reports.

Given the notion that endodontic pain after treatment is the result of periapical inflammation, treatment should be based on the administration of anti-inflammatory medication, such as corticosteroids ${ }^{14}$. This study showed a good tolerability of the use of betamethasone, in the absence of infection reports or other adverse reactions, confirming the results of similar studies although in these the corticosteroid used was dexamethasone, a similar corticosteroid to betamethasone $e^{5,8,10,13-15,20}$. Corticosteroids were used in this study due to their anti-inflammatory power to control pain in endodontics ${ }^{8}$. Corticosteroids have an inhibitory effect on the transcription of the COX-2 enzyme and, consequently, on the synthesis of pro-inflammatory prostaglandins, which may explain the potent anti-inflammatory effect of these agents. On the other hand, they do not exert any effect on the COX-1 expression, which may explain their noninterference in certain biological processes ${ }^{21}$.

Prolonged administration of corticosteroids, such as during the postoperative period may result in suppression of the hypothalamic-pituitary-adrenal axis (HHA), leading to bone mineral loss, causing osteoporosis and may increase the risk of cataracts, glaucoma, cutaneous effects And vascular changes ${ }^{22,23}$, effects on the central nervous system, changes in body fat distribution, increased susceptibility to infection, increased appetite and emotional disturbances ${ }^{24-26}$.

The dose of betamethasone used in this study $(0.05 \mathrm{mg} / \mathrm{kg})$ is 40 times smaller than that of $2 \mathrm{mg} / \mathrm{kg}$ of dexamethasone (which is equipotent to betamethasone), employed by Czerwinsnky et al. $(1972)^{27}$ which, according to these authors, did not produce significant adverse side effects. This also corroborates the results of Mehrvarzfar et al. ${ }^{15}$ (2008) who used a dose of dexamethasone of $4 \mathrm{mg}$ in the periapical region ${ }^{15}$. In fact, there were no reports of adverse effects in relation to the use of betamethasone by patients. This can be explained by the fact that corticosteroids, when used as a single dose or in restricted time periods, are virtually devoid of clinically significant side effects ${ }^{28}$.

In this study, the significant reduction of pain at 4 and 24 hours with the administration of betamethasone corroborates with the results reported by Shantiaee et al. ${ }^{8}$ (2012), although these researchers used dexamethasone. Not having carried out the control of pain after 8 and 12 hours was a limitation of this 
study; the comparison of the results with other studies was only possible in the periods of 4,24 and 48 hours s, $^{8,10,13,15}$.

Betamethasone or dexamethasone at low doses, such as 1 to $2 \mathrm{mg}$, do not produce anti-inflammatory effects that outweigh the suppression of the $\beta$-endorphins involved with the modulation of the pain threshold; consequently they do not decrease pain intensity compared to a placebo ${ }^{29}$. However, doses of 5 to $6.5 \mathrm{mg}$ of dexamethasone (corresponding to 0.07 to $0.09 \mathrm{mg} / \mathrm{kg}$ ) are considered optimal for pain control in endodontic procedures 5 . In this study used a dose of $0.05 \mathrm{mg} / \mathrm{kg}$ and a maximum volume of $1 \mathrm{ml}$, because the place planned for the injection does not support a large volume without exerting discomfort to the patient. However, the dose of $4 \mathrm{mg}$ of betamethasone may be standardized, regardless of body weight, because it does not present risks, and at the same time it avoids unnecessary calculations of dosing and volume of the solution.

Through the data obtained and the comparisons carried out, it is possible to infer that betamethasone was infiltrated through the periapical tissues in sufficient quantities to exert its pharmacological action, which can prove the effectiveness of this corticosteroid by submucosal administration These results are supported by Wayman et al. ${ }^{30}$ (1994), who reported a good distribution of dexamethasone, administered in the mucosa of the vestibule of rat jaws, indicating an affinity of this corticosteroid with bone tissue; and corroborates with the results of Mehrvarzfar et al. ${ }^{15}$ (2008), who tested dexamethasone injected into the periapical region of the treated tooth, with similar results to those of the present study. The main advantages of the submucosal route in relation to the others are the drug concentration near the surgical site and the low systemic absorption of the drug, which consequently results in fewer side effects ${ }^{31}$.

The limitation was the application of a maximum volume of $1 \mathrm{ml}$, equivalent to a dose of $4 \mathrm{mg}$, which has already been demonstrated in previous studies as effective in endodontics ${ }^{32}$.

The lower consumption of analgesics by patients treated with betamethasone confirms the findings by Liesinger et al. ${ }^{5}$ (1993), which showed a consumption of analgesic 2.5 times lower in the group of patients previously treated with corticosteroids compared to those treated with the placebo. Consumption of analgesics indicates the presence of postoperative pain, although there are other possible reasons for this intake, such as pain not associated with endodontic treatment or for prevention of potential pain ${ }^{33}$ - facts that were not reported in this study. There is general agreement that pain is a difficult variable to quantify due to its subjective and multifactorial characteristics ${ }^{34,35}$, which may lead to the occurrence of failures in the evaluations. In this study, the measurement accuracy of the pain experienced by patients also had this limitation, as patients noted their experience of pain intensity subjectively. In addition, another limitation that we must report is that the pain was not measured in the initial period of treatment.

In cases of already installed pain, the use of drugs which directly reduce the activity of nociceptors may be desirable because they can reduce the hyperalgesia - the standard drug in this group being dipyrone ${ }^{36}$. Dipyrone is routinely used in Brazil, Russia, India and other South American, Caribbean, African and Asian countries ${ }^{37-40}$.
It is important to highlight that all patients who reported pain became asymptomatic after 24 hours, result that is very close to that found by Krasner and Jackson ${ }^{13}$ (1986) and Glassman et al. ${ }^{10}$ (1989). Furthermore, no case of flare-up was observed, confirming the results of Imura and Zuolo ${ }^{41}$ and being very close to the results found by Iqbal et al. ${ }^{3}$. The results found by Akbar et al. ${ }^{42}$ (2013) do not corroborate with those reported above, however these authors did not use drugs as postoperative medication.

Another aspect that should be considered is related to the expectation of post-instrumentation pain. When planning an endodontic therapy in previously asymptomatic teeth, the endodontist usually does not prescribe an anti-inflammatory. However, after the procedure and depending on the outcome the professional may choose to prescribe one. In these cases, a simple local infiltration of the corticosteroid in the apical region of the tooth involved may help minimize patient discomfort after the cessation of the effects of local anesthesia.

To control pain and inflammation, the administration of drugs directly on the site of injury may be a more effective action than waiting for absorption through the gastrointestinal tract and distribution by the organism ${ }^{43}$. Thus, administering the drugs submucosally near the tooth's periapex, will presumably reach optimum corticosteroid levels in the inflamed region ${ }^{16}$. This administration may be painless because at the time of application the effect of the anesthetic used in the endodontic procedure will still be present.

In conclusion, betamethasone showed satisfactory effects in the dosage used, as well as in the proposed route of administration. Considering the limitations of this study, this protocol is an advantageous practice due to its effectiveness, and also because of the comfort it provides to patients in the prevention or control of inflammatory pain in endodontics. Further studies should be performed to elucidate possible variations not considered in this study.

\section{Acknowledgments}

Thanks to Prof. Francisco José de Souza Filho (in memoriam), who contributed and revolutionized on the field of endodontics. Thanks to Prof. Joana Ramos Jorge for her contribution in statistics.

The authors have no any conflicts of interest.

\section{References}

1. Roane JB, Sabala CL, Duncanson JG. The balanced force concept for instrumentation of curved canals. J Endod. 1985 May;11(5):203-11.

2. Peters $A O$, Peters IC. Cleaning and shaping of the root canal system. In: Cohen S, Hargreaves MK, editors. Pathways of the Pulp. 9. ed. Saint Louis: Mosby Inc; 2006. p. 290-357.

3. Weine FS, Kelly RF, Lio PJ. The effect of preparation procedures on original canal shape and on apical foramen shape. J Endod. 1975 Aug;1(8):255-62.

4. Bergmans L, Van Cleynenbreugel J, Wevers M, Lambrechts P. Mechanical root canal preparation with NiTi rotary instruments: rationale performance and safety - status report for the American Journal of Dentistry. Am J Dent. 2001 Oct;14(5):324-33. 
5. Gergi R, Rjeily JA, Sader J, Naaman A. Comparison of canal transportation and centering ability of Twisted Files, Pathfile-ProTaper system, and stainless steel hand K-files by using computed tomography. J Endod. 2010 May;36(5):904-7. doi: 10.1016/j.joen.2009.12.038.

6. De-Deus G, Moreira EJ, Lopes HP, Elias CN. Extended cyclic fatigue life of $F 2$ ProTaper instruments used in reciprocating movement. Int Endod J. 2010 Dec;43(12):1063-8.

7. Kiefner $P, B$ Ban $M$, De-Deus $G$. Is the reciprocating movement per se able to improve the cyclic fatigue resistance of instruments? Int Endod J. 2014 May;47(5):430-6. doi: 10.1111/iej.12166.

8. Gambarini G, Rubini AG, Al Sudani D, Gergi R, Culla A, De Angelis F, et al. Influence of different angles of reciprocation on the cyclic fatigue of nickel-titanium endodontic instruments. J Endod. 2012 Oct;38(10):140811. doi: 10.1016/j.joen.2012.05.019.

9. Gambarini G, Gergi R, Naaman A, Osta N, Al Sudani D. Cyclic fatigue of twisted file rotary NiTi instruments used in reciprocating motion. Int Endod J. 2012 Sep;45(9):802-6. doi: 10.1111/j.1365-2591.2012.02036.x.

10. Gergi R, Osta N, Bourbouze G, Zgheib C, Arbab-Chirani R, Naaman A. Effects of three nickel titanium instrument systems on root canal geometry assessed by micro-computed tomography. Int Endod J. 2015 Feb;48(2):162-70. doi: 10.1111/iej.12296.

11. van der Sluis LW, Shemesh H, Wu MK, Wesselink PR. An evaluation of the influence of passive ultrasonic irrigation on the seal of root canal fillings. Int Endod J. 2007 May;40(5):356-61.

12. ElAyouti A, Kiefner P, Hecker H, Chu A, Löst C, Weiger R. Homogeneity and adaptation of endodontic fillings in root canals with enlarged apical preparation. Oral Surg Oral Med Oral Pathol Oral Radiol Endod. 2009 Sep;108(3):e141-6. doi: 10.1016/j.tripleo.2009.04.022.

13. Brunson M, Heilborn C, Johnson DJ, Cohenca N. Effect of apical preparation size and preparation taper on irrigant volume delivered by using negative pressure irrigation system. J Endod. 2010 Apr;36(4):721-4. doi: 10.1016/j.joen.2009.11.028.

14. Silva EJ, Tameirão MD, Belladonna FG, Neves AA, Souza EM, DeDeus G. Quantitative transportation assessment in simulated curved canals prepared with an Adaptive Movement System. J Endod. 2015 Jul;41(7):1125-9. doi: 10.1016/j.joen.2015.02.028.
15. Schneider CA, Rasband WS, Eliceiri KW. NIH Image to ImageJ: 25 years of image analysis. Nature Methods. 2012 Jul;9(7):671-5.

16. Lee TC, Kashyap RL, Chu CN. Building skeleton models via 3-D medial surface/axis thinning algorithms. Comput Vis Graph Image Process. 1994;56:462-78.

17. Schilder $\mathrm{H}$. Cleaning and shaping the root canal. Dent Clin North Am. 1974 Apr;18(2):269-96.

18. Boutsioukis C, Gogos C, Verhaagen B, Versluis M, Kastrinakis E, Van der Sluis LW. The effect of root canal taper on the irrigant flow: evaluation using an unsteady computational fluid dynamics model. Int Endod J. 2010 Oct:43(10):909-16. doi: 10.1111/j.1365-2591.2010.01767.x.

19. Fornari VJ, Silva-Sousa YT, Vanni JR, Pécora JD, Versiani MA, SousaNeto MD. Histological evaluation of the effectiveness of increased apical enlargement for cleaning the apical third of curved canals. Int Endod J. 2010 Nov;43(11):988-94. doi: 10.1111/j.1365-2591.2010.01724.x.

20. De-Deus G, Marins J, Silva EJ, Souza E, Belladonna FG, Reis C, et al. Accumulated hard tissue debris produced during reciprocating and rotary nickel-titanium canal preparation. J Endod. 2015 May;41(5):676-81. doi: 10.1016/j.joen.2014.11.028.

21. Ordinola-Zapata R, Bramante CM, Duarte MA, Cavenago BC, Jaramillo D, Versiani MA. Shaping ability of Reciproc and TF adaptive systems in severely curved canals of rapid microCT-based prototyping molar replicas. J Appl Oral Sci. 2014 Nov-Dec;22(6):509-15. doi: 10.1590/1678775720130705

22. Bürklein S, Schäfer E. Critical evaluation of root canal transportation by instrumentation. Endod Topics. 2013;29:110-24.

23. De-Deus G, Vieira VTL, Silva EJNL, Lopes HP, Elias CN, Moreira EJ. Bending resistance and dynamic and static cyclic fatigue life of Reciproc and WaveOne large instruments. J Endod. 2014 Apr;40(4):575-9. doi: 10.1016/j.joen.2013.10.013.

24. Yoo YS, Cho YB. A comparison of the shaping ability of reciprocating NiTi instruments in simulated curved canals. Restor Dent Endod. 2012 Nov;37(4):220-7. doi: 10.5395/rde.2012.37.4.220.

25. Freire LG, Gavini G, Cunha RS, Santos MD. Assessing apical transportation in curved canals: comparison between cross-sections and micro-computed tomography. Braz Oral Res. 2012 May-Jun;26(3):222-7. 